\section{Elaboração do plano de mobilidade urbana em Natal/RN, Brasil}

\section{(7) Gabriela Baesse}

Programa de Pós-Graduação em Estudos Urbanos e Regionais, Departamento de Políticas Públicas, Centro de Ciências Humanas, Letras e Artes, Universidade Federal do Rio Grande do Norte, Brasil.

Recebido: 5 de febrero de 2018. Aceptado: 14 de agosto de 2018.

\title{
Resumo
}

A mobilidade urbana é um direito social, pois é considerado um direito-meio pelo qual as pessoas conseguem se locomover e assim acessar as diversas estruturas da cidade que concretizam suas necessidades e demandas. A Constituição Brasileira de 1988 determina que é responsabilidade do governo precisar as normas para o desenvolvimento urbano. Em 2012, houve a promulgação da lei 12.587, criando as diretrizes da Política Nacional de Mobilidade Urbana, e instrumentalizando legalmente a criação do Plano de Mobilidade Urbana para uma parte significativa dos municípios que possuem certos atributos. A elaboração do plano permite que cada cidade tenha um plano holístico que atenda às necessidades particulares de cada local. Entretanto, a efetivação da elaboração do plano tem sido um obstáculo para os municípios. Com o intuito de estudar como isto vem transcorrendo através de uma experiência empírica, foi realizado o estudo de caso da cidade de Natal, Brasil, apresentando as dificuldades encontradas pelo poder público local em realizar a execução da lei, e as inquietações suscitadas pelo processo para que de fato se alcance a criação do plano. O trabalho fez uso de uma abordagem qualitativa explicativa. Era inicialmente previsto que a elaboração do plano duraria 10 meses, entretanto seu processo está em seu terceiro ano, sem previsão de finalização.

\section{Elaborating the urban mobility plan in Natal/RN, Brazil}

\begin{abstract}
Urban mobility is a social right, because it is considered a right that gives the way by which people can move around, therefore can access the city structures that materialize their necessities and responsibilities. The 1988 democratic Brazilian Constitution, establish the Brazilian Government as responsible for the urban development regulations. The promulgation of the law 12.587 of 2012, created the guidelines of the Urban Mobility National Policy, that likewise regulated the creation of the Urban Mobility Plan for the
\end{abstract}

\section{Palavras-chave}

Mobilidade urbana Política brasileira de mobilidade urbana

Plano municipal

Natal, Brasil

Key-words

Urban mobility Brazilian policy of urban mobility Municipal plan Natal, Brazil 
municipalities with more than 20.000 inhabitants (or those with specific requirement that also need a Master Plan). The construction of the plan allows each city to have an integrated plan that fulfils its unique needs. Nonetheless, the plan appliance has been difficult for the cities. With the aim to study a case of how this is happening, the city of Natal - Brazil, was chosen to present some difficulties found by the local public power in execute the plan, and worries related with the neglect of that. It was used a qualitative and explanatory approach. It was first previewed that the plan elaboration would endure 10 months, however the process is now in its third year, with no finalization prediction.

\section{Palabras clave}

Mobilidad urbana Política brasilera de movilidad urbana

Plan municipal

Natal, Brasil

\section{Introdução}

A Mobilidade Urbana é um aspecto indissociável da vida nas cidades, pois permite que os habitantes tenham acesso à cidade. Sua dimensão transversal abarca todas as práticas sociais urbanas. É nos deslocamentos que a população tem acesso ao trabalho, estudo, serviços, cultura, ou seja, permite o ir e vir de todos. Além de permitir a efetivação do direito à cidade, a Mobilidade Urbana (MU) é também um direito social. Sua peculiaridade neste sentido está em ser um direito-meio, o que significa que sua concretização permite que vários outros direitos sejam atendidos. A partir deste entendimento, recentemente o transporte foi ratificado no texto constitucional brasileiro como um direito social (Emenda Constitucional no 90 de 15 de setembro de 2015), o que significa que se tornou dever do Estado assegurar a mobilidade urbana, para que todos os cidadãos possam usufruir do atendimento de suas necessidades básicas, e desfrutem de uma vida digna.

O direito à cidade entende ser necessário que os espaços urbanos possam ser acessados de maneira democrática. Entretanto, as cidades foram construídas, planejadas e projetadas para beneficiar o deslocamento rápido e eficiente dos automóveis, em detrimento do transporte público e do deslocamento a pé e de bicicleta, isso ocorre em razão do impacto político e econômico que esse modal tem na história industrial brasileira. O principal problema repousa na relevância que o carro obtém na política de transporte, sua priorização desfavorece a grande parcela da população, que não tem poder aquisitivo suficiente para adquiri-lo.

Ademais, a maior parte dos habitantes das cidades utilizam o transporte público, o caminhar e a bicicleta como meio de transporte para ter acesso aos serviços e infraestruturas urbanas ("Principal meio de locomoção dos brasileiros é andar de ônibus ou a pé", 2015). Uma forma de exemplificar os investimentos com o transporte motorizado individual é a política sistemática feita pelo Estado brasileiro desde a década de 50, que concede vantagens financeiras à indústria automotiva. Schapiro (2017) revela em sua análise que os incentivos tributários para esse segmento não fomentam competências econômicas, ou o desenvolvimento de um novo setor, ao contrário, servem para proteger uma área da indústria.

O modelo atual da mobilidade urbana sustenta-se em uma perspectiva baseada no carro, isso não se limita à parcela da população proprietária do automóvel, pois abarca igualmente a maior parte da população que almeja adquirir um carro, ou veem na construção de ruas para os automóveis um sinal positivo do crescimento econômico e desenvolvimento. O grande desafio está em transformar essa visão para que as políticas públicas passem a priorizar o transporte coletivo e o transporte não-motorizado, se tornando uma política pública de contenção, baseada nos deslocamento real das pessoas (Jones, 2014).

O avanço do setor automotivo foi crucial para o desenvolvimento das cidades que temos hoje, facilitando os deslocamentos de longa distância e colaborando para o 
espraiamento urbano. Entretanto, com o crescimento das cidades, o transporte motorizado individual saturou o uso das ruas, aprofundando os problemas de mobilidade e dificultando ainda mais a locomoção, principalmente para a parcela da população sem acesso ao carro ou moto (Ministério das Cidades Brasil, 2015). A maioria das cidades brasileiras tem um sistema público de transporte ineficiente. Consequentemente aqueles com condições financeiras suficientes escolhem o automóvel como transporte diante da comodidade que fornece, apesar do seu custo elevado. Além disso, inúmeros incentivos fiscais já foram dados pelo Governo Federal brasileiro para que a população compre produtos automobilístico, o que eleva a sua procura, agravando ainda mais a situação. Está lógica aprofunda a desigualdade, ao prover continuamente benefícios para apenas uma parcela da sociedade, em detrimento dos mais pobres que seguem sendo excluídos. (Lima Neto, Carvalho, \& Balbim, 2015).

Os artigos 182 e 183 da Constituição Federal brasileira de 1988 deram origem ao Estatuto da Cidade (2001), que determina diretrizes gerais da política urbana, prevendo instrumentos para garantir o direito à cidade, a função social da propriedade urbana e a democratização da gestão urbana, procurando garantir entre outros, o acesso à infraestrutura urbana, aos serviços públicos e ao transporte. Procurando desenvolver e ampliar o entendimento iniciado no Estatuto sobre o transporte urbano, foi criada a Política Nacional de Mobilidade Urbana (PNMU), que tornou obrigatório que os municípios brasileiros criem o Plano Municipal de Mobilidade Urbana, com o intuito de obter planejamento que atendam às necessidades específicas de cada cidade.

A pesquisa considera a mobilidade urbana como instrumento relevante para a melhoria de vida dos moradores da cidade, em especial os de baixa renda, que são continuamente mais excluídos e marginalizados, alijados do transporte automotivo individual. Melhorar a locomoção das pessoas é essencial para corrigir a injustiça inerente ao modus operandi tradicional, buscando a produção de uma cidade mais igualitária. Consequentemente, a efetivação da PNMU perpassa pela efetivação do Plano, dessa forma, o estudo tem dois objetivos: primeiro, o de elaborar um breve panorama das principais normas brasileiras e do município de Natal que regulam a mobilidade urbana, dando ênfase a Política Nacional de Mobilidade Urbana. O segundo, é apresentar um caso concreto de elaboração do Plano Municipal de Mobilidade Urbana (PlanMob), instrumento da PNMU que visa a organização da mobilidade urbana nas cidades. Com este intuito, apresentamos o processo de elaboração do Plano que tem acontecido no município de Natal, uma das cidades que ainda não cumpriu com a exigência legal de aprova-lo nos moldes da PNMU.

Procurando atender as finalidades supracitadas, optou-se por uma pesquisa de caráter qualitativa explicativa, realizando um estudo de caso do processo de elaboração do Plano de Mobilidade Urbana em Natal. Por meio das análises de notícias e documentos, foi possível obter um entendimento abrangente de como tem ocorrido a produção do plano. Dessa forma, foi possível compreender como tem se dado o processo de elaboração do plano em Natal, viabilizando o entendimento do caso dessa cidade no cenário brasileiro.

\section{A política de mobilidade urbana brasileira}

O órgão do Governo Federal brasileiro responsável pelo auxílio às cidades no financiamento e organização da mobilidade urbana é o Ministério das Cidades (MC), por intermédio da Secretaria Nacional de Transporte e da Mobilidade Urbana (SEMOB). O MC é um dos Ministérios brasileiros mais jovens, criado em 2003, quando a União considerou que era necessária uma instituição específica dedicada a melhoria das cidades. Com o decorrer do tempo, o poder Executivo passa a entender que Mobilidade 
Urbana seria um termo mais abrangente do que transporte público, e que possuía características particulares e desenvolvidas o bastante para legitimar um título autônomo, como é possível observar na Figura 1.

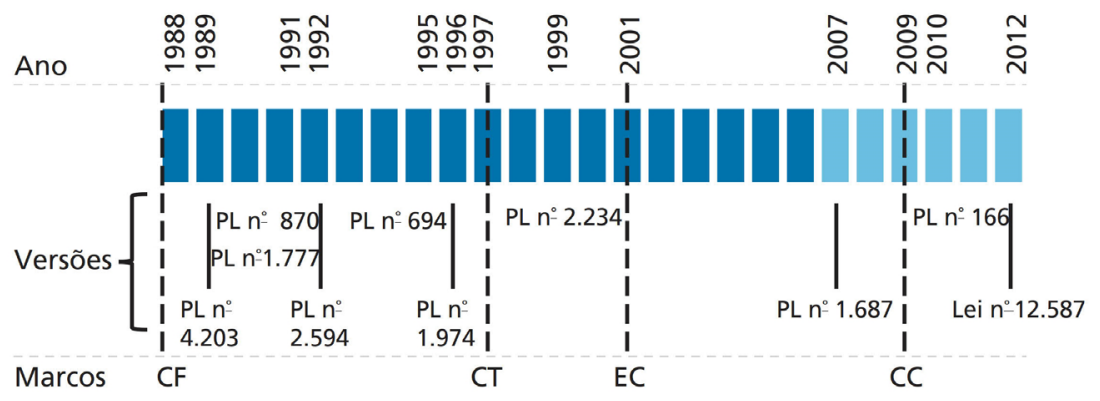

Foco restrito ao transporte público

Foco na mobilidade urbana

Figura 1. Evolução dos projetos de lei sobre transporte e mobilidade urbana pós-CF/1988 (1988-2012). Obs.: CF: Constituição Federal; CT: Código de Trânsito; EC: Estatuto da Cidade; CC: Contribuição do Conselho das Cidades. Fonte e elaboração: Lima Neto \& Galindo, 2015.

Para ampliar esse entendimento, foi criada a Política Nacional de Mobilidade Urbana (Lei $\left.\mathrm{n}^{\circ} 12.587,2012\right)$, uma política de desenvolvimento urbano, com o objetivo de integrar os diferentes modos de transporte e melhorar a acessibilidade e mobilidade das pessoas e cargas no âmbito do município, dando prioridade aos modos de transporte não motorizados e coletivos em detrimento do transporte individual motorizado. A obrigatoriedade de criação do Plano de Mobilidade Urbana recaí nos municípios com mais de vinte mil habitantes, integrantes de regiões metropolitanas ou aglomerações urbanas, onde o poder público pretenda utilizar os instrumentos do $\$ 4^{\circ}$ do art. 182 da Constituição Federal, integrantes de áreas de especial interesse turístico, inseridos na área de influência de empreendimentos ou atividades com significativo impacto ambiental ou aqueles incluídos no cadastro nacional de Municípios com áreas suscetíveis à ocorrência de deslizamentos de grande impacto, inundações bruscas ou processos geológicos ou hidrológicos correlatos.

O Plano é o principal objetivo da lei 12.587/12, pois é essencial como instrumento de concretização da PNMU, tendo em vista que efetiva os princípios, objetivos e diretrizes desta política. A lei estabelece diferentes atribuições para cada ente federativo (Quadro 1), cabendo aos municípios a elaboração do Plano por serem os sujeitos do processo responsáveis pelo planejamento, execução e avaliação da PNMU.

Quadro 1. Atribuição dos Entes Federativos na Política Nacional de Mobilidade Urbana - Lei 12.587/2012. Fonte: Brasil, 2012. Elaboração própria.

\begin{tabular}{|c|c|c|}
\hline \multicolumn{3}{|c|}{ Atribuição dos Entes Federativos na Política Nacional de Mobilidade Urbana - Lei 12.587/2012 } \\
\hline União & Estados & Municípios \\
\hline $\begin{array}{l}\text { Assistência técnica e financeira aos } \\
\text { Estados, DF e Municípios; } \\
\text { Capacitação e desenvolvimento das } \\
\text { instituições nos Estados, DF e Municípios; } \\
\text { Sistema Nacional de Mobilidade Urbana; } \\
\text { Fomentar projetos de grande e média } \\
\text { capacidade, nas aglomerações urbanas e } \\
\text { regiões metropolitanas; } \\
\text { Apoiar ações coordenadas entre municípios } \\
\text { e Estados em áreas cornubadas. }\end{array}$ & $\begin{array}{l}\text { Prestar os serviços de transporte público } \\
\text { coletivo intermunicipais de caráter urbano; } \\
\text { Propor política tributária específica e } \\
\text { de incentivos para a implementação da } \\
\text { PNMU; } \\
\text { Garantir a integração dos serviços nas } \\
\text { áreas que ultrapassam os limites de um } \\
\text { Município. }\end{array}$ & $\begin{array}{c}\text { Planejar, executar e avaliar a Política de } \\
\text { Mobilidade Urbana; } \\
\text { Promover a regulamentação dos serviços } \\
\text { de transporte urbano; } \\
\text { Capacitar pessoas e desenvolver } \\
\text { instituições; } \\
\text { Prestar os serviços essenciais de transporte } \\
\text { público coletivo urbano. }\end{array}$ \\
\hline
\end{tabular}


Gomide e Galindo (2013:33) atribuem essa mudança de ótica a uma modificação do objeto foco das políticas públicas, que não estavam obtendo resultados favoráveis:

No momento de criação do Ministério das Cidades, verificou-se que o objetivo da formulação e implementação de políticas tão somente para o transporte coletivo não seria suficiente para o enfrentamento dos desafios que se colocavam para o desenvolvimento urbano. Desenvolveu-se, assim, um novo conceito que desse conta do novo desafio, o de mobilidade urbana, entendido como as condições de deslocamento das pessoas e bens nas cidades, independentemente do modo de transporte utilizado (coletivo ou individual, motorizado ou não motorizado). A mobilidade urbana, dessa maneira, seria sustentável quando promovesse o acesso universal das pessoas à cidade - e às oportunidades que ela oferece - contribuindo para o desenvolvimento socioeconômico, sem agredir o meio ambiente e usando a infraestrutura viária de forma racional. Essa foi a base para a formulação do projeto de lei pelo Poder Executivo entre 2004-2006 (PL n.1.687/2007) que culminou com a promulgação da Lei de Diretrizes da Política Nacional de Mobilidade Urbana (Lei n.12.587/2012).

Por meio da Política Nacional de Mobilidade Urbana (Lei 12.587/12) e do documento federal intitulado PlanMob: caderno de Referência para elaboração de Plano de Mobilidade Urbana (Brasil 2015; Ministério das Cidades Brasil, 2015), observa-se a visão adotada pelos órgãos acerca da $\mathrm{MU}$, que prioriza o transporte não motorizado e o transporte público coletivo, e adotando a definição da mobilidade urbana sustentável, que procura levar em conta os fatores econômicos, sociais e ambientais envolvidos na temática. Entretanto, apesar dessa perspectiva ser adotada, o que se observa na prática são políticas públicas que dão pouco suporte à implementação do transporte coletivo e não motorizado. (Kneib, 2012)

\section{A situação da mobilidade urbana em Natal/RN}

A cidade de Natal, capital do Estado do Rio Grande do Norte, tem uma população de 803.739 (IBGE, 2015). A cidade tem uma baixa densidade demográfica em decorrência do espalhamento do seu território. Alguns dos principais problemas de mobilidade urbana em Natal estão atrelados ao transporte público, que conta uma frota de ônibus antiga, com linhas que ainda utilizam trajetos determinados na década de 80, não acompanhando as transformações da cidade e a infraestrutura pouco funcional para o pedestre. O Plano de Mobilidade Urbana seria uma forma de trazer mudanças para o atual funcionamento das redes de transporte na cidade, que se apresentam obsoletas, e traria uma priorização de modos de deslocamento coletivos e não motorizados, aspecto fundamental para que seja possível uma cidade que atenda a toda a sua população e não exacerbe ainda mais suas desigualdades. (Torquato, 2006)

Em Natal, o órgão responsável por formular, acompanhar e executar políticas públicas de mobilidade urbana é a Secretaria Municipal de Mobilidade Urbana (STTU), que tem como incumbência regulamentar os serviços de ônibus, táxis e transportes opcionais exclusivamente dentro do território do município, com a finalidade de atender ao interesse público. É também atribuição do órgão o planejamento da mobilidade urbana da cidade, desenvolvendo e incentivando políticas para melhorar o funcionamento da mobilidade e a qualidade de vida da população. Outra secretaria que não atua diretamente, mas que pode tomar decisões importantes relacionadas à isso, é a Secretaria de Meio Ambiente e Urbanismo (SEMURB), que tem a tarefa de organizar o território, tendo em vista que é o órgão responsável pelo planejamento urbanístico e ambiental. 
Segundo dados de 2000, do Departamento Estadual de Trânsito do Rio Grande do Norte (DETRAN - RN), entre 1980 e 1999, a frota de veículos motorizados de Natal cresceu de forma vertiginosa, indo de 01 veículo para cada 20 habitantes para 01 veículo para cada 4,5 habitantes (Torquato, 2006) e, utilizando os dados mais atuais do Departamento Estadual de Trânsito do RN (Departamento Estadual de Trânsito do RN, 2016), Natal tem atualmente 01 veículo particular para cada 3,65 habitantes. Esse aumento é percebido na diminuição da velocidade da operação do sistema de transporte e nos congestionamentos cada vez mais habituais, ampliando a necessidade de efetivamente construir um sistema integrado de mobilidade urbana.

Outro aspecto que com o passar dos anos influenciou a malha urbana da cidade foi o fato da sua geomorfologia estar envolta por barreiras físicas e naturais resguardadas pelo Plano Diretor que cria as Zonas de Proteção Ambiental (ZPAs), o que faz com que vários dos corredores estruturantes da cidade acompanhem o contorno dessas áreas (Figura 2), essas vias são importantes por compreender boa parte do fluxo de veículos em Natal. (Morais, 2010)

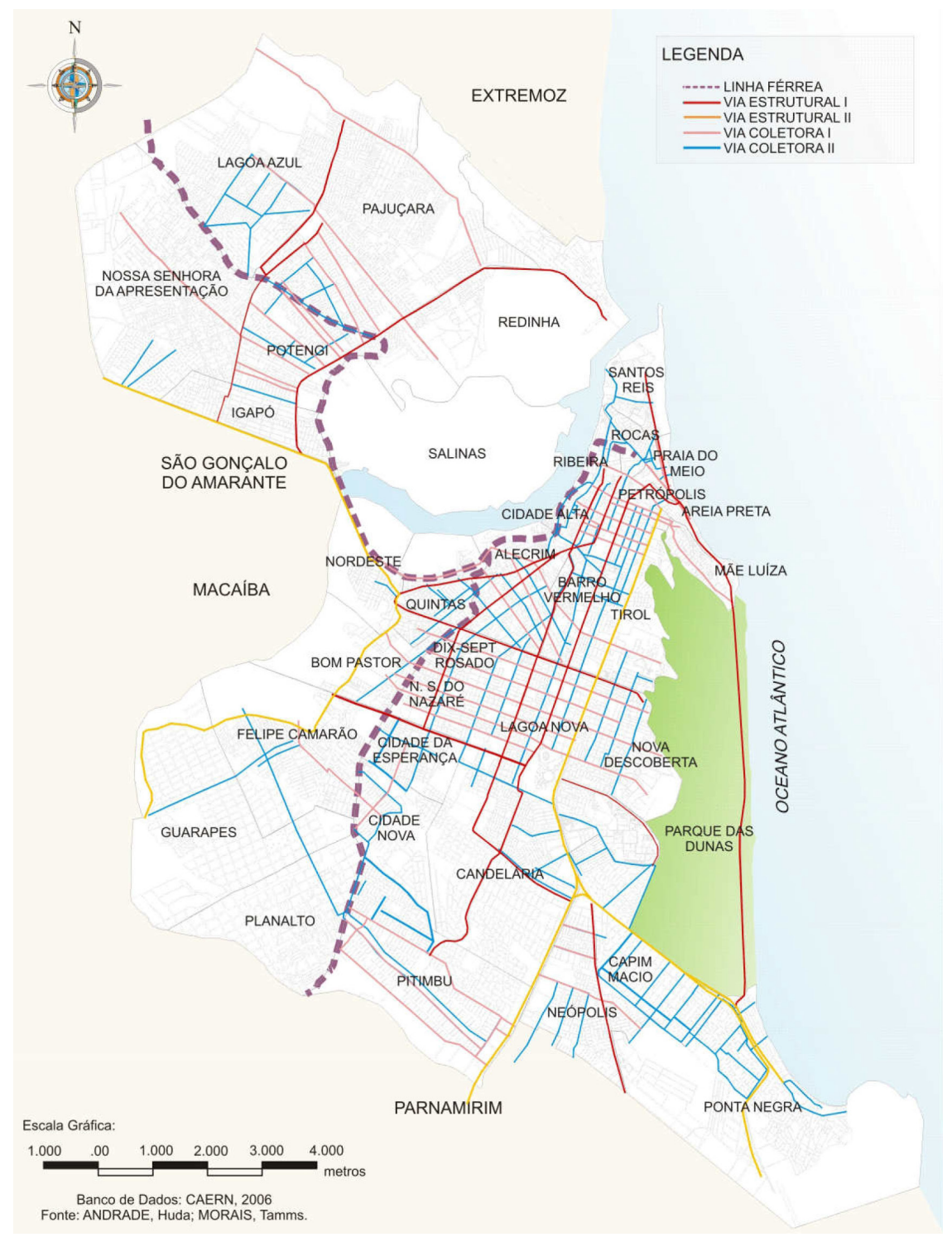

Figura 2. Mapa de vias estruturais e coletoras. Fonte e elaboração: Planmob, 2011. 
Existem ainda na cidade usuários desproporcionais do solo no município, tal como a Universidade do Rio Grande do Norte, a Petrobras, as unidades militares e o Centro Administrativo do Governo Estadual. Além disso, Natal tem várias áreas verdes de preservação no seu território, como o Parque Estadual Dunas de Natal (conhecido como Parque das Dunas, criado em 1977). A existência desses espaços em uma quantidade e porte significativos, colaboram para a descontinuidade urbana, fazendo com que haja uma ocupação extensiva na cidade, com diversos vazios e com uma densidade mais baixa. Sem dúvida, esses espaços não são de todo prejudiciais, também colaborando intensivamente para o aumento da qualidade de vida, pois constituem o símbolo e identidade paisagística do município, fornecendo áreas verdes e diminuindo a poluição. Por outro lado, o aumento das distâncias amplia os gastos com a urbanização.

A organização atual é configurada por segregação espacial, um reflexo do uso tardio de instrumentos de planejamento e da ocupação desordenada. Isto faz com que a população mais abastada da cidade more na parte mais favorecida com infraestrutura urbana e serviços, enquanto os habitantes com menor renda vivem em locais mais distantes e com infraestrutura precária. A Zona Norte é a mais prejudicada, por ser uma área majoritariamente habitacional que possuí apenas duas vias de acesso para o escoamento do trânsito, pois é necessário transpor o Rio Potengi mediante o uso de pontes. Dessa forma, essa região administrativa é que confronta os piores engarrafamentos ocasionados pela demasiada quantidade de veículos, realizando uma média de duas horas de viagem em cada deslocamento diário, sendo também a mais extensa e populosa parte da cidade. (Torquato, 2006)

O documento que atualmente regula a mobilidade urbana em Natal é o Plano Diretor (Natal, 2007), que define em seu Artigo $6^{\circ}$, Inciso XXXI, a mobilidade urbana como "conjunto de serviços que visem o deslocamento de pessoas, bens e mercadorias em todos os níveis, coordenados pelo Poder Público". Além disso, o Plano fala da política de mobilidade urbana em seu Título IV.

Art. 57-A Política de Mobilidade Urbana será instituída pelo Poder Público Municipal no prazo máximo de 2 (dois) anos.

Art. 58 - A Política de Mobilidade Urbana deverá:

I - Ser instrumento de inclusão social ampliando a mobilidade da população, promovendo o acesso físico a serviços e equipamentos públicos, ao lazer e a integração social;

\section{$[\ldots]$}

Art. 59 - Os planos e projetos específicos de mobilidade urbana deverão atender ao Plano Diretor de Mobilidade Urbana, instrumento básico da política de Mobilidade Urbana, considerando:

I - A utilização racional do espaço de circulação urbana através da priorização da circulação de pedestres em relação aos veículos e do transporte coletivo em relação ao transporte individual;

II - O fortalecimento de uma rede de transporte coletivo de qualidade e ambientalmente sustentável através da implantação progressiva de tecnologias não poluentes ou de baixo teor de poluição e acessíveis aos portadores de deficiências físicas e mobilidade reduzida, da integração física e tarifária, da melhoria das condições de conforto e segurança nos pontos de parada e da adoção de medidas de incentivo ao uso do sistema de transporte coletivo nos deslocamentos diários; 


\begin{abstract}
III - A implantação da rede viária do transporte não motorizado através da previsão de espaços seguros para a circulação de veículos não motorizados, da ampliação de calçadas nas áreas de maior concentração de pedestres e da adoção de padrões construtivos para estas vias.
\end{abstract}

\title{
$[\ldots]$
}

VII -A adequação da rede viária principal com vistas à melhoria do desempenho da rede de transporte coletivo, em termos de rapidez, conforto, segurança e custos operacionais; VIII - a criação de vias-parque que delimitem e protejam as áreas de interesse de preservação ambiental e se configurem em área de lazer. (Natal, 2007).

Os artigos do Plano Diretor têm uma visão adequada às necessidades que precisam ser atingidas para a obtenção de uma política pública mais democrática e que proporcione deslocamentos mais dinâmicos, inclusive já prevendo antes mesmo da lei federal a confecção de uma Política de Mobilidade Urbana para a cidade, isso provinha do Estatuto da Cidade que já abordava a criação dos Planos Diretores de Mobilidade Urbana (PDMU - instrumento análogo ao PlanMob). Entretanto, de acordo com Meira (2013), os gestores públicos brasileiros sentem-se desencorajados a implementar políticas de mobilidade urbana que restringem o uso do automóvel por serem medidas impopulares, visto que as classes mais altas são prejudicadas, sendo igualmente os atores políticos mais influentes e formadores de opinião. Soma-se a isso a falta de planejamento e os embates do espaço urbano e do transporte, fazendo com que seja necessária uma grande vontade política para materializar uma mobilidade urbana como a estabelecida legalmente. É um desafio colocar em prática o que é determinado pela legislação, pois os interesses econômicos e políticos geralmente se sobreporem aos interesses sociais (Araújo et al. 2011).

O Plano Diretor de Natal, em seu Artigo 116, estabelece que sua revisão deve acontecer a cada quatro anos, para que a legislação se adapte às mudanças da cidade. A última revisão deveria ter acontecido em 2011, porém somente em 2015 a Secretaria Municipal de Meio Ambiente e Urbanismo (SEMURB) iniciou a revisão do Plano internamente, e anunciou que a revisão pública aconteceria em março de 2016. Contudo, as revisões públicas apenas foram iniciadas no segundo semestre de 2017, e não tiveram continuidade, encontrando-se atualmente estagnadas.

A exigência legislativa de que os municípios devem elaborar um Plano de Mobilidade, foi uma iniciativa fundamental, pois, como colocam Machado e Pichini (2018:74), o Plano "deve apresentar as ações para materializar os objetivos e metas que pretendem resolver os problemas e as necessidades da população, identificados através de diagnósticos e da participação dos atores sociais". A contrapartida exigida pela União é o impedimento de aquisição de recursos federais para a realização de projetos de mobilidade por parte das cidades que não finalizarem a elaboração dos planos no prazo estabelecido. Assim, foi estipulado a princípio pelo Governo Federal, um período de três anos para que os municípios criassem os planos. Nesse cenário, o prazo teria expirado em maio de 2015, contudo, um levantamento do Ministério das Cidades mostrou que após a conclusão do prazo, apenas 5\% dos 3.341 municípios obrigados a terem o plano, conseguiram efetuá-lo. Dessa forma, foi realizada uma mudança no prazo. Justificou-se que uma grande parcela da população seria prejudicada com o impedimento de receber auxílios para a área, tendo em vista que muitas cidades dependem dos recursos para executar suas obras. Assim, o parágrafo que estipula esse tempo foi alterado duas vezes em 2016 e mais uma vez em 2018, estando válida a redação da Medida Provisória ${ }^{\circ}$ 818/18. (Janary Junior, 2016) 
Com isso, atualmente os municípios têm até maio de 2019 para concluírem seus respectivos planos. Antes da extensão do prazo, Natal se encontrava inadimplente com a elaboração, e não podia receber investimentos na área de mobilidade urbana. Com as mudanças de data de entrega dessa ferramenta de planejamento, a capital potiguar tem ainda - um curto - tempo para que a conclusão seja feita.

A concretização do Plano de Mobilidade passa por várias etapas. Aqui o enfoque está em observar alguns procedimentos gerenciais e o entrave na fase de elaboração (elemento 3 e 4 da Figura 3).

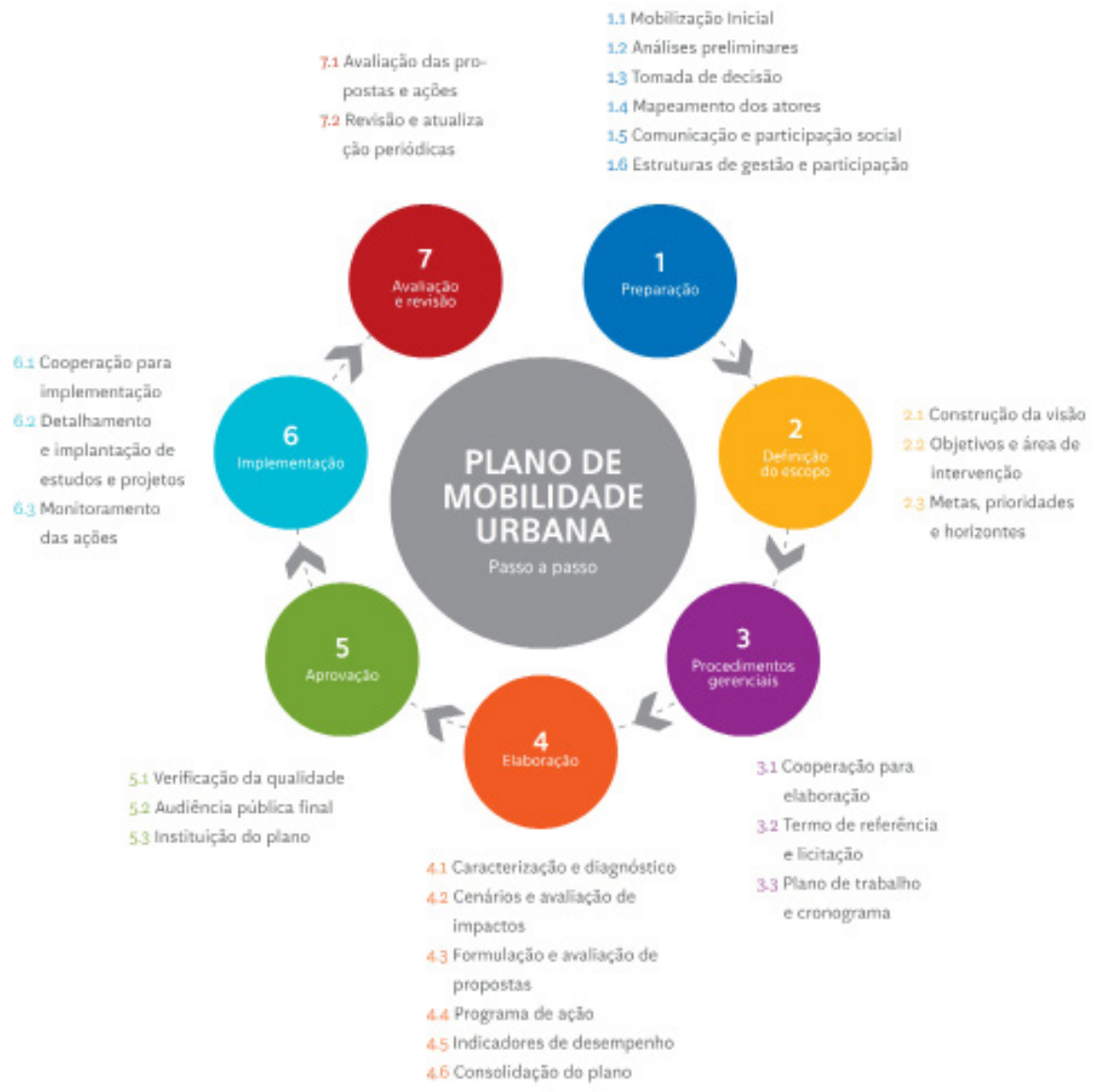

Figura 3. Passo a passo e respectivas atividades para um Plano de Mobilidade Urbana. Fonte: EMBARQ Brasil. Elaboração: Ministério das Cidades Brasil, 2015.

\section{Contratempos na elaboração do PlanMob}

Como abordado anteriormente, a Lei 12.587/12 foi um marco crucial para a mobilidade urbana brasileira, demonstrando uma mudança no modelo de planejamento tradicional do transporte urbano, que anteriormente direcionava sua atenção apenas para a eficácia do fluxo e tráfego de transporte motorizado, especialmente para o carro. $\mathrm{O}$ foco, então, passou a ser um planejamento integrado com a "política de desenvolvimento urbano e respectivas políticas setoriais de habitação, saneamento básico, planejamento e gestão do uso do solo no âmbito dos entes federativos" (Brasil, 2012). Além disso, a criação de um Plano para cada cidade resulta em um uso mais proveitoso dos recursos, visto que incluí todos os modais no planejamento, incentivando a articulação entre os diferentes meios de transporte e pensando a cidade de maneira holística, atendendo a demanda e funcionamento próprio de cada município. (Caccia, 2015) 
Apesar do Plano Diretor tratar de forma genérica a organização que a mobilidade urbana deveria seguir, ele prevê a criação da Política de Mobilidade Urbana para a cidade no prazo de dois anos, o que potencialmente criaria um planejamento de mobilidade integrado da cidade a ser seguido, levando em conta de forma estruturada as necessidades do município. Com esse intuito, em 2008, a Prefeitura Municipal de Natal contratou a Fundação Coordenação de Projetos, Pesquisas e Estudos Tecnológicos (COPPETEC) da Universidade Federal do Rio de Janeiro (Contrato no 012/2008) - para a elaboração do plano, o prazo no contrato estabelecia a entrega para dezembro do mesmo ano.

Entretanto, o documento não é entregue no período determinado. Seguidamente foram sendo feitos aditivos ao contrato, o relatório final não é vinculado no Diário Oficial do Município (DOM). No dia 01/07/2011, o DOM diz que o plano ainda estava sendo finalizado, mas não se estipula datas de quando isso aconteceria. Posteriormente, na ata da Reunião Extraordinária do Conselho da Cidade no dia 16 de agosto de 2013 é feita a apresentação do Plano de Mobilidade, somente 5 anos após o início do processo.

Apesar do plano nunca ter sido divulgado para o devido conhecimento da sociedade e não ter promovido a participação da população, a análise posterior dos relatórios da COPPETEC demonstram um alinhamento com a perspectiva de cidade promovida na Lei $12.587 / 12$, pois atentava para a necessidade de o município realizar o gerenciamento da demanda de transporte, tendo em vista que é preciso entender o real uso do transporte feito na cidade para que seja realizado um planejamento adequado as suas necessidades. Porém, a Prefeitura nunca chega a usar de fato o plano feito pela COPPETEC.

Em 2012, com a Lei 12.587, passa a ser obrigatório que Natal apresente seu Plano de Mobilidade para que possa continuar recebendo investimentos federais na área, mas o Plano iniciado em 2008 em nenhum momento é apontado como uma possibilidade para atender aos requisitos da lei. Somente em 2014 se inicia o processo licitatório para contratar uma empresa com o objetivo de elaborar o Plano de Mobilidade. No mesmo ano, a Secretaria suspendeu duas vezes a licitação. A primeira suspensão aconteceu no dia da abertura das propostas de licitação, em 25 de setembro de 2014. A STTU afirmou que houve uma grande procura de empresas, contudo a suspensão ocorreu para que fossem feitos ajustes no edital a fim de que ficasse mais claro o que estava sendo requerido. A previsão dada na época pelo presidente da Comissão Permanente de Licitação (CPL) da STTU, Josemar Tavares Júnior, era de que no mais tardar o edital seria publicado em novembro de 2014. ("Licitação da bilhetagem eletrônica nos transportes de Natal está sem data - Tribuna do Norte”, 2016)

Em outubro de 2014 outra vez o edital é publicado e suspenso em decorrência de que o documento foi impugnado por uma das empresas participantes, questionando alguns requisitos exigidos pela STTU no edital. Em março de 2015, o processo é finalizado e a Prefeitura Municipal de Natal contrata a empresa especializada para o desenvolvimento do plano, a Tectran - Técnicos em Transporte LTDA, sediada na cidade de Belo Horizonte - Minas Gerais, através do contrato no 002/2015 - STTU. O serviço de consultoria pactuado pelo valor de $\mathrm{R} \$ 671.500,00$ (seiscentos e setenta e um mil e quinhentos reais), a princípio o prazo de vigência do contrato é de 13 meses consecutivos, e o de execução do Plano era de 10 meses. Nessa previsão inicial, o plano seria entregue em janeiro de 2016. (Natal, 2015a)

O edital de contrato entre a Prefeitura e a Tectran prevê a realização de 8 atividades, cada uma culminando com a entrega de um produto (Quadro 2). Juntos, os produtos compõem o PlanMob. 
Quadro 2. Produtos previstos no edital do Plano Municipal de Mobilidade Urbana de Natal. Fonte: Prefeitura Municipal de Natal (2014), elaboração própria.

\begin{tabular}{|l|c|}
\hline Atividade & Produto \\
\hline Atividade 1 & Planejamento Executivo \\
\hline Atividade 2 & Relatório do Diagnóstico e Tendências \\
\hline Atividade 3 & Plano de Gestão da Demanda \\
\hline Atividade 4 & Plano de Melhoria da Oferta \\
\hline Atividade 5 & Plano de Circulação Viária \\
\hline Atividade 6 & Plano de Implantação, Gestão e Monitoramento \\
\hline Atividade 7 & Minuta de Lei e Audiências Públicas \\
\hline Atividade 8 & Relatório final \\
\hline
\end{tabular}

Apesar das datas estipuladas quando o contrato foi firmado, somente em fevereiro de 2016 houve a cerimônia de divulgação do Plano. Posto isso, o plano já começou suas atividades públicas com atraso no tocante a data estipulada inicialmente, já estava em vigor o aditivo número 1 que prorrogou a entrega até maio de 2016 (Quadro 3). $\mathrm{Na}$ ocasião foi apresentado o planejamento e cronograma da empresa para realiza-lo, divulgando que a primeira etapa já estava em andamento - etapa de Planejamento Executivo e Levantamento de Dados. Além disso, a consultora do projeto ressaltou durante a oportunidade, a importância da participação da sociedade civil nas discussões, o Plano seria pautado na valorização do transporte coletivo, a pé e de bicicleta. Após essa apresentação, ainda no mês de fevereiro de 2016, foram realizadas quatro audiências públicas nas quatro regiões administrativas da cidade, com o intuito de escutar as demandas da população em relação a mobilidade urbana. (Natal 2016a; 2016b)

Quadro 3. Aditivos no Contrato do Plano de Mobilidade Urbana de Natal - RN. Fonte: Natal 2015b; Natal 2016b; Natal 2017a; Natal 2017b. Elaboração própria.

\begin{tabular}{|l|c|c|c|}
\hline Documento & $\begin{array}{c}\text { Data de publicação no } \\
\text { DOM }\end{array}$ & $\begin{array}{c}\text { Prazo final para } \\
\text { execução }\end{array}$ & $\begin{array}{c}\text { Tempo acumulado } \\
\text { desde o início do } \\
\text { processo }\end{array}$ \\
\hline Contrato & $\mathrm{mar} / 15$ & $\mathrm{jan} / 16$ & 10 meses \\
\hline Aditivo $\mathrm{n}^{\circ}$ 01 & $\mathrm{nov} / 15$ & $\mathrm{mai} / 16$ & 15 meses \\
\hline Aditivo $\mathrm{n}^{\circ}$ 02 & $\mathrm{ago} / 16$ & $\mathrm{mai} / 17$ & 27 meses \\
\hline Aditivo $\mathrm{n}^{\circ}$ 03 & $\mathrm{jun} / 17$ & $\mathrm{dez} / 17$ & 34 meses \\
\hline Aditivo $\mathrm{n}^{\circ}$ 04 & $\mathrm{dez} / 17$ & $\mathrm{dez} / 18$ & 46 meses \\
\hline
\end{tabular}

Durante a cerimônia, a Tectran divulgou a criação do site (http://www.planmobnatal. com.br/), onde era possível avaliar online as condições de mobilidade na cidade, baixar documentos produzidos ao longo do desenvolvimento do Plano, registrar sugestões para melhorar o sistema de mobilidade e acessar a agenda de eventos. Contudo, desde o início de 2018, o site encontra-se fora do ar, não sendo mais possível acessá-lo.

Após as audiências iniciais realizadas em 2016, houveram apenas três ocasiões em que a população foi chamada presencialmente a acompanhar o projeto. Houve uma reunião feita ainda no mesmo ano, em 10 de outubro, unicamente com o objetivo de apresentar e aprovar o cronograma de elaboração do PlanMob. Nessa ocasião o Secretário Adjunto da Secretaria Municipal de Mobilidade Urbana (STTU), Walter Pedro da Silva, afirmou que apesar das mudanças da Lei 12.587/12 que estenderam o prazo para entrega do PlanMob, ele seria a prioridade do setor até sua conclusão. Nesse momento ficou estabelecido que sua finalização ocorreria até 31 de maio de 2017 (Quadro 3), quando seria encaminhada a Minuta de Lei do Plano de Mobilidade de Natal para Procuradoria e disponibilizado os Produtos Consolidados no site (Natal, 2016c; Natal, 2016d).

O único evento divulgado no site posteriormente as audiências, foi a oficina realizada em novembro de 2016, que discutiu com a população as propostas para o 
plano de gestão de demanda (atividade 3) de cada modal (bicicleta, pedestre, ônibus etc.), pois de acordo com Walter Pedro da Silva: "A proposta da oficina serve para isso: para projetarmos a cidade a partir dos interesses comuns da população" (Natal, 2016e).

O último encontro organizado pela Prefeitura e Tectran para tratar do PlanMob, aconteceu em junho de 2017, quando foi feita a oficina sobre o Plano de Circulação Viária de Natal (atividade 5). O objetivo era apresentar uma proposta de traçado para a cidade, prevendo a construção de novos corredores viários para serem implementados à longo prazo. Durante a reunião, os grupos da sociedade civil organizada, ali presentes (Universidade Federal do Rio Grande do Norte, Associação de Ciclistas do Rio Grande do Norte, Associação Potiguar Amigos da Natureza, Observatório Social de Natal entre outros) criticaram os corredores viários planejados, pois estes ainda tinham como foco somente os veículos, não prevendo calçadas, corredor para ônibus ou estruturas para os ciclistas, como enfatiza a Política de Mobilidade Urbana. Além disso, criticaram não haver detalhamentos de melhorias para a Zona Norte da cidade, área onde se estão os maiores gargalos do tráfego ("Grupo da STTU discute Plano de Circulação Viária e Mobilidade”, 2017; Torquato, 2006).

O quadro 3 lista os aditivos realizados no Contrato do PlanMob Natal, mostrando as datas em que houve a publicação do documento e o prazo final que havia sido estabelecido para que a empresa concluísse o plano. Destaca-se que o processo de elaboração, que estava previsto para acontecer em 10 meses, já ultrapassa 3 anos, e caso não ocorra mais nenhum aditivo, o Plano de Mobilidade será finalizado com 46 meses de duração, ou 3 anos e 10 meses.

Transcorrido mais de um ano entre a última manifestação da Prefeitura Municipal de Natal e da finalização deste artigo, ainda não se sabe quando haverá a entrega do Plano de Mobilidade Urbana do Município de Natal. Embora a Secretaria de Mobilidade Urbana tenha manifestado em diversas ocasiões que estaria priorizando a finalização do Plano, não é o que tem acontecido. Apesar do munícipio não se encontrar mais inadimplente com a entrega do documento - como seria o caso se a Lei 12.587/12 não tivesse sido modificada -, o ideal seria que sua finalização acontecesse da maneira mais célere possível. Posto que, a entrega do plano tem o papel fundamental de planejar, organizar e melhorar as condições da mobilidade urbana da cidade, sua entrega permitiria o adiantamento de medidas integralizadas de mobilidade, proporcionando o funcionamento de um sistema mais perspicaz.

\section{Discussão sobre o plano: comparativo e encaminhamentos ferramentas de efetivação}

Com o intuito de contextualizar as dificuldades que estão sendo enfrentadas pelo município de Natal dentro de um cenário mais abrangente, está última subparte se debruça em apresentar sinteticamente outras experiências, iniciando pelo contexto europeu, modelo que a Lei 12.587/12 baseou-se, e discorrendo sobre a situação dos municípios brasileiros, seus principais entraves e realizando uma análise crítica da situação.

Os estudos acerca da etapa de elaboração dos planos de mobilidade ainda são escassos, a maioria dedica-se nas questões da implementação. A efetivação de uma política de mobilidade urbana é bastante desafiadora, constatamos isso ao observar a experiência europeia, região onde é possível encontrar a maior parte das experiências exitosas na mudança de paradigma da mobilidade urbana e na implementação de sistemas de 
gestão da MU. A Comunidade Europeia (CE) tem construído sua política desde 1996 (EC, 2001), incluindo pesquisa, desenvolvimento de projetos e um investimento superior a 10 bilhões de euros, entretanto o bloco de países ainda enfrenta contratempos na transformação total do panorama da mobilidade urbana.

Isto ocorre em decorrência do processo da política de mobilidade relacionar-se com outros aspectos que os gestores precisam defrontar nas cidades, como lidar com a expansão urbana e com as "pressões exercidas pela especulação imobiliária e pelos interesses econômicos, bem como da mudança e do apoio da população." (Machado \& Piccinini, 2018, p. 86) Entretanto, no contexto europeu, é preciso considerar que não se trata apenas de uma nação, mas de um bloco econômico e político composto de Estados Membros, em que aplica-se o princípio da subsidiariedade, ou seja, a mobilidade urbana é principalmente responsabilidade dos governos locais, sendo uma recomendação e não imposição, mas tendo o apoio do bloco na estruturação da política, no financiamento, na troca de experiência e na sensibilização. Há várias diferenças políticas, econômicas, sociais, culturais, morfológicas e do caráter geral entre cada cidade, que ficam ainda mais evidentes dentro de contextos nacionais díspares. Porém o cenário europeu é também discrepante da realidade de um país continental como o Brasil. Outros Estados também seguiram o modelo da União Europeia (UE) para a criação da sua própria política nacional de mobilidade urbana, como o México e a Índia.

Uma diferença fundamental entre a construção do plano no Brasil e na Europa, é que na UE se estabelece como ponto de partida a vontade local de melhorar a mobilidade e a qualidade de vida dos cidadãos, por meio do desenvolvimento de uma visão comum sobre o assunto e pelo acordo entre todas as partes sobre as responsabilidades gestoras e financeiras para tornar o plano minimamente exequível (Wefering et al. 2014), ou seja, é necessário um plano estratégico consistente para o setor e cidade em questão. Como o plano não é uma imposição para as cidades europeias, isso faz com que os municípios que a ponham em prática, o façam por ter essa vontade política, através de uma autonomia na tomada de decisão, fazendo com que a cidade esteja envolvida e disposta a enfrentar os desafios para mudar o funcionamento da dinâmica local.

De uma forma simplificada, a elaboração do PMUS [Plano de Mobilidade Urbana Sustentável] pressupõe um plano estratégico pensado para atingir resultados consistentes, com uma missão e objetivos definidos em conjunto com os atores (participação), para alcançar um modelo de cidade futura (visão), em um determinado período de tempo (prazo) monitorado por indicadores. [...] as medidas sugeridas, são comuns nos guias de elaboração encontrados na literatura. (Machado \& Piccinini, 2018:80-81, grifo da autora).

Quando o estágio da elaboração é feito de maneira consistente, empregando um processo sólido, aumenta-se a probabilidade de as etapas seguintes serem efetivadas. Ao construir um plano executável, fundado na visão comum dos atores envolvidos localmente com a questão, obtém-se um documento de fato elaborado para e por aqueles na cidade. Isso facilita o encaminhamento das etapas seguintes de aprovação e implementação, indo além de um plano governamental, torna-se uma política pública construída em conjunto, que irá além do mandato em questão, e envolverá atores comprometidos em exercer pressão social para garantir a continuidade do processo.

O levantamento realizado em 2016 pela Secretaria Nacional de Transporte e da Mobilidade Urbana (SNTMU), revelou a situação da elaboração dos planos nos municípios brasileiros. Dos 5.569 municípios brasileiros, $60 \%$ deles entram no escopo da lei, necessitando elaborar o plano. Dentre estes, observou-se que algumas cidades não 
responderam ao ofício enviado (37\%, contra $63 \%$ que respondeu), a taxa de respondentes cresce conforme o porte do município. Verificou-se também que apenas uma minoria dos municípios possui um PlanMob, enquanto a maioria não está sequer elaborando-o (Figura 4).

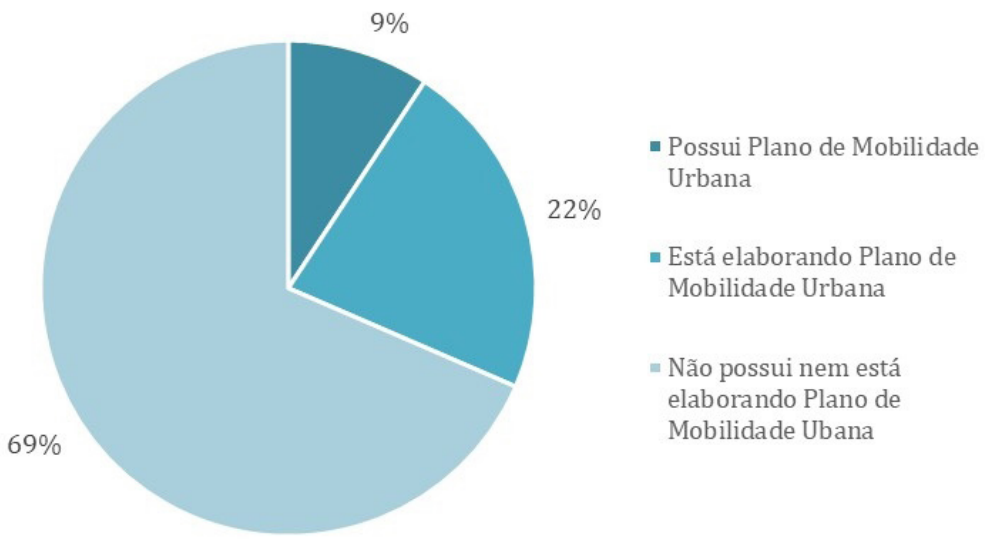

Figura 4. Situação dos municípios na elaboração do Plano de Mobilidade Urbana. Fonte: SNTMU, 2016. Elaboração própria.

A figura 5 revela que a elaboração do plano de mobilidade urbana no Brasil está proporcionalmente vinculada ao tamanho do município. Quanto maior a cidade, maior a chance de haver um plano, ou seja, o alto índice de municípios sem plano da Figura 4 é resultado principalmente dos municípios de menor porte, que reconhecidamente possuem maior dificuldade técnica e econômica para produzir documentos como este, muitos sendo majoritariamente dependentes de repasses estaduais e federais. Natal encontra-se entre os municípios de 500 mil a 1 milhão de habitantes, a cidade está atrasada se comparada com seus pares, onde $50 \%$ deles já têm o plano.

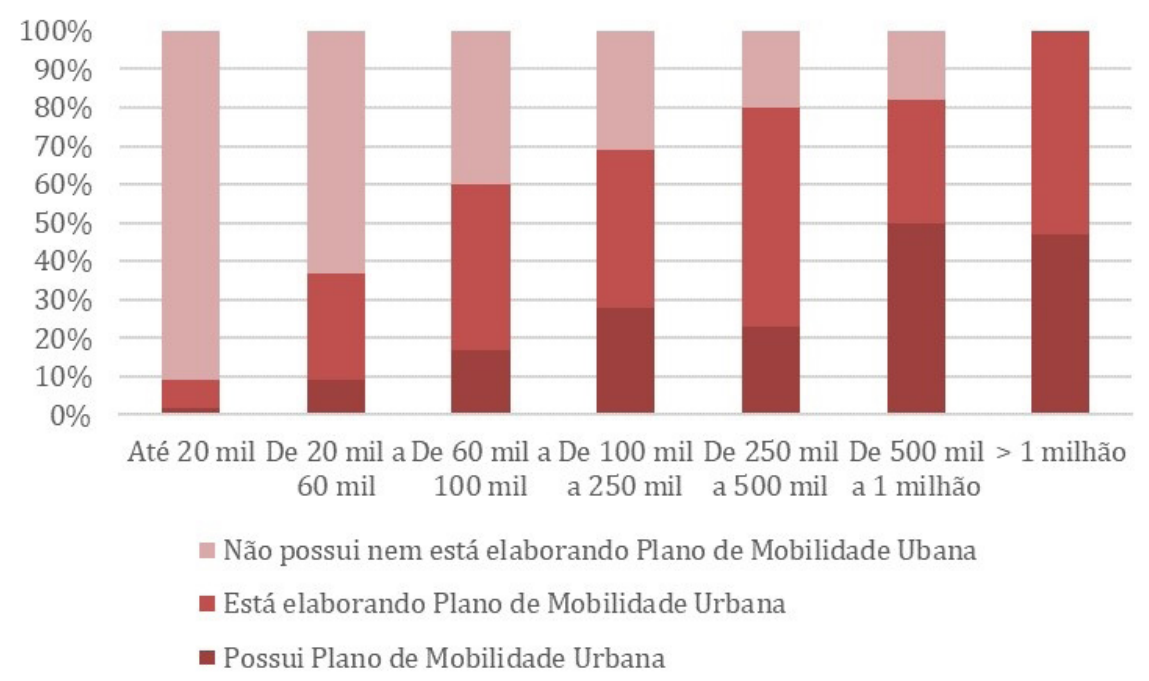

Figura 5. Situação dos municípios na elaboração do Plano de Mobilidade Urbana por número de habitantes. Fonte: SNTMU, 2016. Elaboração própria. 
Os problemas de mobilidade tornam-se igualmente mais intricados com o aumento da quantidade de habitantes, complexificando o planejamento urbano e consequentemente o Plano de Mobilidade. Ao considerar somente os municípios com população superior a $250 \mathrm{mil}, 84 \%$ deles possuem o plano ou estão elaborando-o, o que pode ser considerado um percentual positivo pois demonstra que a grande maioria das cidades de médio e grande porte caminham para ter uma mobilidade urbana mais estruturada, porém esses números não indicam necessariamente que os planos estão de acordo com a PNMU, nem tampouco que a implementação aconteça.

O que tem limitado o avanço da elaboração e implementação dos planos é primeiramente o paradigma focado no transporte individual, que engessa a prefeitura em projetos voltados para o carro. Um exemplo é a prefeitura de São Paulo, que apesar de ter aprovado o PlanMob em 2015, em decorrência da mudança de gestão em 2017 tem retrocedido em várias das ações realizadas com a aprovação do plano. Atualmente a cidade tem voltado a assumir uma perspectiva automobilística, aumentando a velocidade nas avenidas marginais da cidade e dificultando a construção de ciclovias e ciclofaixas (Basilio, 2017; Lobel, 2017).

Os maiores obstáculos dos municípios são de ordem técnica e financeira. Muitas cidades não possuem pesquisa e conhecimento no setor da mobilidade ou do trânsito, e nem mesmo um corpo técnico apto a elaborar o plano. Mesmo quando possuem um órgão específico que se dedique à mobilidade, isso não garante que há uma integração suficiente para que o municípios coordene o plano e os projetos decorrentes dele (Costa, 2016).

Na falta de um corpo técnico que tenha os meios hábeis de elaborar o plano, os municípios precisam desembolsar dinheiro para a contratação de uma empresa de consultoria que o faça, entretanto, não são todas as cidades que possuem os recursos para tal fim. A solução para isso é realizar o financiamento do plano, as cidades de menor porte podem fazer isso através de recursos da União, mas de acordo com José Roberto Generoso (2017), secretário de Transporte e da Mobilidade Urbana do Ministério das Cidades (SEMOB), os prefeitos preferem efetuar gastos em obras de infraestrutura, como a construção de praças, parques, ruas etc. do que com um plano. Nesta situação, evidenciada pelo próprio setor responsável pelo assunto nacionalmente, caberia procurar saídas como a da União Europeia, que realiza campanhas de sensibilização para evidenciar a importância e ganhos que os municípios de diferentes portes alcançam com o Plano de Mobilidade. Inclusive sendo previsto no artigo 16, Inciso I da Lei a responsabilidade do governo brasileiro em prestar a assistência técnica e financeira aos municípios (Brasil, 2012).

Muitas vezes a contratação de uma empresa de consultoria é a solução encontrada pelos municípios para superar suas limitações, entretanto não é a opção ideal. Pois mesmo com o edital de licitação prevendo o acompanhamento do órgão responsável pela mobilidade, esse processo retira a participação direta do município na produção do PlanMob, tornando seu envolvimento mais adjacente e desfavorecendo o desenvolvimento da visão institucional acerca da mobilidade urbana. No Brasil, a perspectiva da mobilidade urbana ainda está sendo construída, passando de uma visão centrada no transporte motorizado individual para uma visão mais abrangente que abarca o transporte coletivo e não motorizado, e isso ainda não foi absorvido pelos gestores locais. Dessa maneira, a elaboração do plano pelo próprio setor técnico do município possivelmente permite o aperfeiçoamento da compreensão da perspectiva da Política Nacional de Mobilidade Urbana, que coloca o transporte público e a mobilidade não motorizada como prioridade.

Contudo, a realidade da gestão pública não permite trabalhar com as condições ideais. Diante do corpo técnico limitado, muitos municípios, como Natal, precisam utilizar-se 
da ferramenta de contratação de empresa consultoria para conseguirem encaminhar o Plano de Mobilidade Urbana. É preocupante o caso da capital potiguar, em que já ao final da confecção do Plano, tem a sua continuidade interrompida sem justificativa, isso atesta uma ineficiência do município. A entrega do plano por si só já proporcionaria grandes benefícios para a cidade, mas para isso aconteça é preciso que a Secretaria de Mobilidade Urbana informe à população o motivo do atraso e se responsabilize em pressionar a empresa e aplicar as penalidades dispostas no edital de licitação, se for o caso.

\section{Considerações finais}

A partir do contexto aqui apresentado sobre o processo de formulação do Plano de Mobilidade Urbana de Natal-RN, verifica-se que não houve sua priorização por parte da Prefeitura Municipal de Natal, ou da Secretaria Municipal de Mobilidade Urbana. Desde 2013, a mesma gestão está à frente do poder executivo, não tendo havido mudanças institucionais que poderiam modificar contundentemente a agenda municipal.

Inicialmente, pareceu haver celeridade em encaminhar o processo de licitação, pois os trabalhos começaram em 2014, mesmo após o governo ter assumido em 2013 com a cidade em condições dificultosas, após a gestão de Micarla de Sousa, envolvida e condenada em crimes de desvio de dinheiro e associação criminosa, tendo sido inclusive afastada do cargo (Araújo 2016). Porém, após o início, o processo de contratação da empresa se arrastou por um ano, e a maior delonga começou após a finalização desta primeira etapa.

Acredita-se que a priorização inicial que foi dada ao Plano, pode ser consequência da conjuntura política da época, tendo em vista que o país e o município vivenciaram intensas reivindicações em torno do transporte nas Jornadas de Junho de 2013, também chamadas de Manifestações dos 20 centavos por protestarem contra o aumento do valor da passagem do transporte público.

A despeito da elaboração do plano ter sido delegada à uma empresa de consultoria, cabe ao órgão público como requerente, fiscalizar e pressionar o andamento do processo. A morosidade para sua conclusão é prejudicial para o próprio plano, que tem os dados e etapas já finalizados sendo progressivamente defasados. O município de Natal precisa pressionar a empresa, tomando as medidas cabíveis diante do atraso excessivo, como a exigência do pagamento das multas referentes.

Questiona-se a importância que o município atribuí a organização da mobilidade urbana, já que houve um plano concluído que nunca foi utilizado como base para projetos e para o planejamento da Secretaria. Mesmo que seu escopo não estivesse totalmente de acordo com a normativa da 12.587 de 2012, ele tinha direcionamentos importantes para a construção de uma percepção mais integral da mobilidade na capital norte Riograndense. Portanto, o município causa a impressão de estar apenas cumprido a prerrogativa da lei, sem a real preocupação do ordenamento urbano.

Antes do estancamento da discussão do PlanMob Natal, que ocorreu após junho de 2017, o processo estava acontecendo de acordo com a Política Nacional de Mobilidade Urbana, que vindica que seu desenvolvimento seja participativo, através de audiências e consultas públicas e com procedimentos sistemáticos de comunicação, de avaliação da satisfação dos cidadãos e dos usuários e de prestação de contas públicas - que estavam sendo feitos a partir do site e através de audiências e reuniões. Desde então, não houve mais manifestação de como está o andamento da elaboração do PlanMob, e o site que 
permitia acessar as informações, que era o meio que fornecia informações acerca do processo, encontra-se inacessível.

O último aditivo feito ao contrato da empresa que detém a responsabilidade de produzir o PlanMob o estende até final de 2018, porém, diante de tantas mudanças já realizadas, e de um grande período de silêncio do município de Natal e da Tectran sobre os encaminhamentos necessários para a conclusão, não é possível prever quando isso acontecerá. Suscita também a dúvida se a finalização ocorrerá na data deste último aditivo, e caso isso não aconteça, é possível que se ultrapasse o prazo final estabelecido na Política Nacional de Mobilidade Urbana para maio de 2019.

O governo municipal de Natal não tem mostrado ações satisfatórias para dar encaminhamento à finalização do PlanMob. Uma saída possível para esse estancamento, seria através da aplicação das multas previstas no edital (Natal, 2014) de contratação, fazendo uso das penalidades do Artigo 86 da Lei 8.666/93 (Brasil, 1993). A prática adotada pelo município de executar aditivos para aumentar o prazo de entrega do documento, gera o entendimento de que existe razões para a finalização do plano não ser uma prioridade. Também cogita-se a possibilidade da cidade estar sem recursos para continuar o pagamento da consultoria. O processo ressalta a complexidade e falta de clareza, características identificadas por Zahariadis (1999) no processo de formulação de políticas públicas.

A população seria quem mais se beneficiaria com a entrega do Plano de Mobilidade Urbana, pois estaria presenciando a criação de um planejamento holístico dos deslocamentos, integrando diferentes modos de transporte e focando em formas de locomoção que diminuem as desigualdades, proporcionando uma qualidade de vida mais evidente para os habitantes. Acrescenta-se que a gestão municipal se tornaria mais eficaz e efetiva à longa prazo, transformando a maneira como as pessoas transitam no espaço urbano e eliminando algumas das adversidades que hoje enfrentam.

Contudo, surge o receio do PlanMob tornar-se um instrumento como o Plano Diretor de Natal, que apesar de ter um ordenamento amplo e interessante, não consegue ser aplicado pela Prefeitura Municipal do Natal. O que impediria que isso corresse com o PlanMob, é o detalhamento presente no plano, que por meio dos produtos elaborados direciona de maneira mais concreta os encaminhamentos após sua aprovação, incluindo diagnósticos da situação da mobilidade e direcionamentos das ações posteriores para atender as necessidades específicas de Natal e de seus cidadãos. Pois como coloca Flávio Villaça (1999) existe um abismo entre o discurso e a prática, o que faz com que os investimentos conduzam a tomada de decisão. Dessa forma, seria necessário um amplo comprometimento da gestão municipal.

O trabalho buscou discutir acerca das práticas de gestão e planejamento no que tange o Plano Municipal de Mobilidade Urbana de Natal, destacando a importância do tema para um desenvolvimento urbano democrático e os obstáculos que sua elaboração tem enfrentado. Diante da análise feita, pode-se considerar que a formulação do PlanMob teve um início promissor após sua licitação, porém se encontra em um momento de estancamento. Apesar do prejuízo que a falta do plano traz para a cidade, até 2019 não haverá impedimentos para adquirir recursos federais, entretanto a delonga e falta de posicionamento governamental geram inquietação, pois não se sabe se sua conclusão acontecerá até o prazo estipulado.

Agradeço o financiamento da Coordenação de Aperfeiçoamento de Pessoal de Nivel Superior (CAPES), da Pró-Reitoria de Pós-Graduação e do Programa de Pós-Graduação em Estudos Urbanos e Regionais (PPEUR) da Universidade Federal do Rio Grande do Norte. 


\section{Q Bibliografia}

»Araújo, M. R. M. de, Oliveira, J. M. de, Jesus, M. S. de, Sá, N. R. de, Santos, P. A. C. dos, \& Lima, T. C. (2011). Transporte público coletivo: discutindo acessibilidade, mobilidade e qualidade de vida. Psicologia \& Sociedade, 23(3), 574-582. https:// doi.org/10.1590/S0102-71822011000300015.

» Araújo, R. (2016, agosto 2). Micarla de Sousa é condenada a 16 anos. Tribuna do Norte. Recuperado de http://www.tribunadonorte.com.br/noticia/micarla-desousa-a-condenada-a-16-anos/353947.

»Basilio, A. L. (2017, novembro 18). Carta Capital. Lei sancionada por Doria põe em xeque ciclovias e ciclofaixas. Recuperado de https://www.cartacapital.com. $\mathrm{br} / \mathrm{sociedade/lei-sancionada-por-Doria-poe-em-xeque-ciclovias-e-ciclofaixas}$

» Brasil, G. F. do. Lei no 8.666 de 1993. Normas para licitação e contratos da Administração Pública., Pub. L. No. 8.666 (1993). Recuperado de http://www. educacao.sp.gov.br/a2sitebox/arquivos/documentos/951.pdf.

» Brasil, G. F. do. Lei no 10.257 de 2001. Estatuto da Cidade, Pub. L. No. 10.257, Brasília (2001). Recuperado de http://www.planalto.gov.br/ccivil_03/leis/ LEIS_2001/L10257.htm.

»Brasil, G. F. do. Lei no 12.587 de 2012. Política Nacional de Mobilidade Urbana, Pub. L. No. 12.587 (2012). Recuperado de http://www.planalto.gov.br/ccivil_03/_ ato2011-2014/2012/lei/l12587.htm.

» Brasil, M. das C. (2015). PlanMob: caderno de Referência para elaboração de Plano de Mobilidade Urbana. Recuperado de http://www.cidades.gov.br/ images/stories/ArquivosSE/planmob.pdf.

" Caccia, L. S. (2015). Mobilidade urbana: políticas públicas e apropriação do espaço em cidades brasileiras (Dissertação). Universidade Federal do Rio Grande do Sul, Porto Alegre.

" Costa, L. C. (2016). Desafios na elaboração dos planos de mobilidade municipais. Revista Técnica da CNM, 176.

" Departamento Estadual de Trânsito do RN, D. (2016). Relatório estatístico da frota de veículos até dezembro de 2016. Recuperado de http://adcon.rn.gov.br/ acervo/detran/doc/DOCoooooooo0160544.PDF.

" Generoso, J. R. (2017, agosto 29). Ministério incentiva elaboração de planos de mobilidade antes do prazo-limite Agência Brasil. Recuperado de http:// agenciabrasil.ebc.com.br/geral/noticia/2017-08/ministerio-incentiva-planosde-mobilidade-prazo-limite.

» Globo (2015, outubro 14). Principal meio de locomoção dos brasileiros é andar de ônibus ou a pé. Recuperado 23 de novembro de 2015, de http://g1.globo. com/economia/noticia/2015/10/principal-meio-de-locomocao-dos-brasileirose-andar-de-onibus-ou-pe.html.

» Gomide, A. de Á., \& Galindo, E. P. (2013). A mobilidade urbana: uma agenda inconclusa ou o retorno daquilo que não foi. Estudos Avançados, 27(79), 27-39. https://doi.org/10.1590/S0103-40142013000300003.

" Grupo da STTU discute Plano de Circulação Viária e Mobilidade. (2017, junho 11). Recuperado 9 de abril de 2018, de http://www.tribunadonorte.com.br/noticia/ 
grupo-da-sttu-discute-plano-de-circulaa-a-o-via-ria-e-mobilidade/382919.

»IBGE. (2015). Censo demográfico 2015. Recuperado de https://cidades.ibge.gov. $\mathrm{br} / \mathrm{brasil} / \mathrm{rn} / \mathrm{natal} /$ panorama.

" Janary Junior. (2016, outubro 14). Câmara dos Deputados. MP prorroga para 2019 prazo para município elaborar Plano de Mobilidade Urbana. Recuperado de http://www2.camara.leg.br/atividade-legislativa/comissoes/comissoespermanentes/cpd/noticias/mp-prorroga-para-2019-prazo-para-municipioelaborar-plano-de-mobilidade-urbana.

" Jones, P. (2014). The evolution of urban mobility: The interplay of academic and policy perspectives. IATSS Research, 38(1), 7-13. https://doi.org/10.1016/j. iatssr.2014.06.001.

»Kneib, E. C. (2012). Mobilidade Urbana e Qualidade de Vida: do panorama geral ao caso de Goiânia. Revista UFG, (12).

» Licitação da bilhetagem eletrônica nos transportes de Natal está sem data. (2016, dezembro 20). Tribuna do Norte. Recuperado de http://www. tribunadonorte.com.br/noticia/licitaa-a-o-da-bilhetagem-eletra-nica-nostransportes-de-natal-esta-sem-data/366903.

»Lima Neto, V. C., Carvalho, C. H. R. de, \& Balbim, R. N. (2015, novembro). Instituto de Pesquisa Econômica Aplicada - IPEA. Mobilidade urbana: o Brasil em transformação. O papel do IPEA na construção do pacto da mobilidade. Texto para discussão 2148.

" Lima Neto, V. C., \& Galindo, E. P. (2015). Planos de Mobilidade urbana: instrumento efetivo da política pública de mobilidade? Brasília : Rio de Janeiro: Instituto de Pesquisa Econômica Aplicada - IPEA. Recuperado de http://ipea. gov.br/agencia/images/stories/PDFs/TDs/td_2115.pdf.

»Lobel, F. (2017, dezembro 3). Acidentes com mortes nas marginais contrariam discurso da gestão Doria. Folha de São Paulo. Recuperado de https://www1. folha.uol.com.br/cotidiano/2017/12/1940174-acidentes-com-mortes-nasmarginais-contrariam-discurso-da-gestao-doria.shtml.

" Machado, L., \& Piccinini, L. S. (2018). Os desafios para a efetividade da implementação dos planos de mobilidade urbana: uma revisão sistemática. URBE. Revista Brasileira de Gestão Urbana, 10(1), 72-94. https://doi. org/10.1590/2175-3369.010.001.a006.

» Meira, L. H. (2013). Políticas públicas de mobilidade sustentável no Brasil: barreiras e desafios. (Tese). Universidade Federal de Pernambuco, Recife.

" Morais, T. M. da C. (2010). Espaço de pobreza e mobilidade urbana: os deslocamentos da população de baixa renda em Natal/RN. Universidade Federal do Rio Grande do Norte. Programa de Pós-Graduação em Arquitetura e Urbanismo (Dissertação). Universidade Federal do Rio Grande do Norte, Natal.

» Natal, P. M. de. Plano Diretor de Natal, Pub. L. No. Lei Complementar 82 (2007). Recuperado de https://www.natal.rn.gov.br/semurb/paginas/File/ InstrOrdSearch/24_Plano_Diretor.pdf.

»Natal, P. M. de. (2014) Edital do processo 031806/2014-65, Pub. L. No. 031806/2014-65.

» Natal, P. M. de. (2015) Contrato no 002/2015.

» Natal, P. M. de. (2015) Termo aditivo no 001 ao contrato no 002/2015, Pub. L. No. 001. 
"Natal, P. M. de. (2016) Termo aditivo no 002 ao contrato no 002/2015.

»Natal, P. M. de. (2016b, fevereiro 16). Município apresenta Plano de Mobilidade Urbana de Natal. Recuperado 24 de janeiro de 2018, de http://natal.rn.gov.br/ noticia/ntc-23539.html.

"Natal, P. M. de. (2016c, outubro 31). Ata de reunião de audiência para apresentação e aprovação do cronograma de elaboração do Plano Diretor de mobilidade urbana do Natal realizada em 31 de outubro de 2016. Recuperado de https://drive.google. com/drive/folders/oBzPAcXvi12EmZFlvMUs2U2JsY2s.

"Natal, P. M. de. (2016d, outubro 31). Cronograma versão 1. Recuperado de https://drive.google.com/drive/folders/oBzPAcXvi12EmZFlvMUs2U2JsY2s.

»Natal, P. M. de. (2016e, novembro 18). Plano de demandas para mobilidade é discutido com população. Recuperado 24 de janeiro de 2018, de http://www. natal.rn.gov.br/noticia/ntc-25021.html.

»Natal, P. M. de. (2017). Termo aditivo no 003 ao contrato no 002/2015.

»Natal, P. M. de. (2017). Termo aditivo no 004 ao contrato no 002/2015.

"Schapiro, M. G. (2017). O estado pastor e os incentivos tributários no setor automotivo. Revista de Economia Política, 37(2), 437-455. https://doi. org/10.1590/0101-31572017v37no2a10.

" Torquato, A. M. S. C. (2006). Transporte e exclusão social: investigando conexões em um bairro do Natal-RN. (Dissertação em Engenharia Civil). Universidade Federal de Pernambuco, Recife.

»Villaça, F. (1999). Uma contribuição para a história. In Deak, c. Schiffer, S. R. (org.), O processo de Urbanização no Brasil. (p. 169-243). São Paulo: Editora da Universidade de São Paulo.

»Wefering, F., Rupprecht, S., Bührmann, S., \& Böhler-Baedeker, S. (2014). Guidelines: developing and implementing a sustainable urban mobility plan. Bruxelas: Rupprecht Consult, European Commission.

»Zahariadis, N. (1999). Ambiguity, Time and Multiple Streams. In P. Sabatier (Org.), Theories of the Policy Process (p. 73-93). Boulder: Westview.

\section{Gabriela Baesse / gbaesse@gmail.com}

Graduada em Relações Internacionais (Universidade Potiguar) e em Gestão de Políticas Públicas (Universidade Federal do Rio Grande do Norte), mestranda no Programa de Pós-Graduação em Estudos Urbanos e Regionais (Universidade Federal do Rio Grande do Norte). Membro do Observatório das Metrópoles. Apresentou trabalhos no Congresso Brasileiro de Direito Urbanístico e no Congreso Internacional de Urbanismo em Oaxaca - México. 